\title{
Rapport au Conseil du Patrimoine ethnologique sur le thème «Culture technique » (1987)
}

\section{François Sigaut}

\section{(2) OpenEdition}

1 Journals

\section{Édition électronique}

URL : https://journals.openedition.org/artefact/7593

DOI : 10.4000/artefact.7593

ISSN : 2606-9245

Éditeur :

Association Artefact. Techniques histoire et sciences humaines, Presses universitaires du Midi

\section{Édition imprimée}

Date de publication : 18 juin 2015

Pagination : 131-162

ISBN : 978-2-271-08155-1

ISSN : 2273-0753

\section{Référence électronique}

François Sigaut, «Rapport au Conseil du Patrimoine ethnologique sur le thème "Culture technique » (1987) », Artefact [En ligne], HS 01 | 2015, mis en ligne le 29 avril 2021, consulté le 05 mai 2021. URL : http://journals.openedition.org/artefact/7593; DOI : https://doi.org/10.4000/artefact.7593

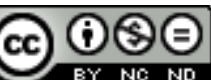

Artefact, Techniques, histoire et sciences humaines est mise à disposition selon les termes de la Licence Creative Commons Attribution - Pas d'Utilisation Commerciale - Pas de Modification 4.0 International. 


\section{Rapport au Conseil du Patrimoine ethnologique sur le thème "Culture technique » (1987)}

François SIGAUT

\section{Avant-propos}

Les techniques et la technographie

Savoirs, pratiques, tâches, apprentissage

Le groupe social comme lieu de production simultanée de l'efficacité, du sens et de l'identité

Culture technique et patrimoine

Récapitulation des suggestions

\section{Avant-Propos}

Le thème de ce rapport, la culture technique, ne correspond pas à l'un seulement des appels d'offres lancés par la Mission du Patrimoine ethnologique depuis sa création. Un comptage sommaire fait apparaître, en effet, que sur les dix appels d'offres qui ont été lancés (auxquels s'ajoutent deux autres rubriques), quatre seulement n'ont donné lieu à aucune opération touchant de près ou de loin ce thème de la culture technique. Les résultats de ce comptage sont les suivants:

\begin{tabular}{|l|c|c|}
\hline \multicolumn{1}{|c|}{ Appels d'offres } & \multicolumn{2}{c|}{ Nombre d'opérations } \\
\hline & Total & $\begin{array}{c}\text { Touchant au thème } \\
\text { culture technique }\end{array}$ \\
\hline Famille et parenté & 18 & 0 \\
\hline Savoirs naturalistes & 35 & 13 \\
\hline Fait industriel & 65 & 30 \\
\hline Techniques menacées & 9 & 9 \\
\hline Ethnologie urbaine & 24 & 0 \\
\hline France pluriethnique & 21 & 0 \\
\hline Identité et régions & 31 & 0 \\
\hline Pratiques rituelles & 13 & 2 \\
\hline Ethnomusicologie & 16 & \\
\hline
\end{tabular}




\begin{tabular}{|l|c|c|}
\hline \multicolumn{1}{|c|}{ Appels d'offres } & \multicolumn{2}{c|}{ Nombre d'opérations } \\
\hline & Total & $\begin{array}{c}\text { Touchant au thème } \\
\text { culture technique }\end{array}$ \\
\hline Consommations familiales & 19 & 2 \\
\hline Groupements «patrimoine» & 13 & 5 \\
\hline Autres études & 27 & 2 \\
\hline Totaux & $\mathbf{2 9 1}$ & $\mathbf{6 4}$ \\
\hline
\end{tabular}

Ce comptage ayant été fait sur la base du simple intitulé des opérations, la marge d'erreur est assurément importante. Admettons cependant, au moins à titre d'hypothèse, cette proportion de 64 opérations sur 291, soit $22 \%$, qui porteraient plus ou moins sur le thème de la culture technique. C'est une proportion relativement élevée, et qui paraît largement supérieure au poids relatif donné à ce thème dans le milieu ethnologique en général. Cela n'est sans doute pas un hasard. De tradition ancienne, les ethnologues européanistes se sont toujours davantage intéressés aux techniques que leurs collègues exotisants. D'autre part, on assiste depuis une quinzaine d'années au développement d'une véritable mode des techniques dites anciennes ou traditionnelles. Mode qui se manifeste bien sûr au premier chef dans le milieu des collectionneurs et des musées, mais dont chacun peut également constater combien elle est devenue prégnante dans le milieu de la publicité. Il n'est guère douteux que cette mode est née en réaction à la soudaineté des changements qui sont intervenus au cours des «trente glorieuses » et au climat de crise qui s'est installé depuis lors (la chose est particulièrement évidente en agriculture).

Quoi qu'il en soit, et quelques sommaires que soient ces remarques, elles font apparaître un premier problème: le décalage entre la «demande» qui se manifeste sous cette forme de mode, et les moyens intellectuels que nous avons $\mathrm{d}^{\prime} \mathrm{y}$ répondre. Le milieu universitaire (CNRS et institutions similaires y compris) n'était pas prêt à accueillir cette demande en 1975. L'est-il davantage aujourd'hui? On peut en discuter, et la conclusion varierait d'ailleurs beaucoup d'une région à l'autre. Ce qui nous importe ici, c'est que seul l'établissement d'un lien solide entre "universités» et «musées» peut garantir l'avenir de tout ce qui sera entrepris dans le domaine de la culture technique. Faute d'appui universitaire, on voit bien que les opérations muséales sont vouées à la répétition et à l'ennui, quand ce n'est pas à la célébration de valeurs douteuses. Et faute d'appui muséal (sous forme de contraintes, éventuellement), les universitaires ne pourront que céder toujours plus à l'inclination spontanée qui les porte vers toujours plus d'abstraction. Tout cela est absolument banal. Mais c'est une banalité bien mal partagée encore, s'il faut en croire les apparences, et qu'il n'est donc peut-être pas inutile de rappeler une fois de plus.

Mais d'autres difficultés doivent être évoquées, qui sans être tout à fait spécifiques au domaine, peut-être, y ont cependant une grande importance. Elles se manifestent, par exemple, dans le vocabulaire: ni le terme de culture, ni celui de technique, ni ceux de pratique, de savoir, de 
savoir-faire, etc., ne font l'objet d'un accord général. Et il est clair que ce n'est pas une simple question de vocabulaire, mais d'un problème de fond, dont les implications sont multiples, et qui ne sera pas résolu à court terme. Car une double réalité est en cause: l'extrême hétérogénéité $\mathrm{du}$ domaine auquel tous ces mots-clefs font référence, et l'hétérogénéité à peine moindre des disciplines et des approches qui s'efforcent d'en connaître.

Sur le second point, il est facile de donner une idée de la situation. Il suffit en effet de rappeler que presque toutes les branches des sciences humaines interviennent dans ce domaine: l'ethnologie, l'histoire et la linguistique bien entendu, mais aussi et de plus en plus l'archéologie (qui a maintenant étendu son champ jusqu'au contemporain), la psychologie et l'ergonomie, sans oublier la géographie, la sociologie et l'économie qui tendent aujourd'hui à redécouvrir un thème qu'elles ont longtemps négligé. Cette multiplication des approches n'est pas une mauvaise chose en soi, puisqu'elle répond à une réelle complexité du sujet. Mais elle pose naturellement des problèmes d'intercompréhension. Problèmes qu'il faudra bien résoudre, car la situation ne paraît pas près de se stabiliser. La tendance n'est certainement pas à un partage bien propre, bien cartésien, du domaine entre toutes les disciplines. La tendance paraît bien plutôt à la concurrence entre disciplines, et à l'éclectisme (quoi que le terme soit inadéquat) dans les recherches de terrain. L'archéologie contemporaine, l'ethno-archéologie, la psychologie interculturelle, etc., empiètent sur les terres les plus traditionnelles des ethnologues. Et réciproquement, ethnologues, socio- logues, géographes, etc., n'hésitent plus à emprunter des parts majeures de leur problématique aux sciences cognitives ou à l'économie. On a un peu l'impression d'un grand orchestre dans lequel, lassés de jouer toujours le même genre de musique, les instrumentistes s'essayeraient à jouer les instruments de leurs collègues. On ne peut pas encore savoir ce qui sortira de cette situation. Je dois dire, à titre personnel, que je la trouve plutôt stimulante et plaisante.

Mais au-delà de ce mélange des genres, qui annonce peut-être une redistribution meilleure, il y a l'hétérogénéité du domaine lui-même. Toute activité matérielle met en œuvre un ensemble d'éléments que nous désignons par les termes de techniques, savoirs, savoirfaire, habiletés, croyances, raisonnements, etc. Éléments indissociables dans la réalité de la pratique, puisqu'ils sont tous nécessaires (ou estimés tels par les agents) à l'obtention du résultat. Mais éléments extraordinairement hétéroclites, et dont il est donc très difficile de rendre compte par l'observation et l'analyse. Sans traiter la question au fond, il n'est pas inutile, peut-être d'essayer de nous faire une idée plus concrète de ces difficultés à l'aide de quelques exemples. Et pour plus de clarté encore, prenons ces exemples dans des cas extrêmes, pour ainsi dire.

Premier cas extrême, une industrie dite de processus (cimenterie, raffinerie de pétrole, chimie lourde...). Là en apparence, l'intervention humaine est réduite à presque rien: des tâches de surveillance et de commande, médiatisées elles-mêmes par tout un appareillage aboutissant souvent à une salle unique. Et surtout, la totalité du processus peut 
être décrite dans les termes des sciences de la nature (géométrie, physique, chimie) ce qui signifie qu'en principe, absolument toutes les connaissances nécessaires au bon fonctionnement de l'usine sont explicites: il $n^{\prime} y$ a pas un boulon, pas une valve, pas un fil électrique dont l'existence n'ait été prévue et calculée. Si bien que l'usine existe entièrement sur le papier avant d'exister sur le terrain. On peut faire des études sociologiques ou économiques autour d'une telle usine. Mais à première vue, on n'y peut plus faire d'études technologiques, puisque toute la technologie a été faite avant que l'usine n'existe'.

À l'opposé, comment allons-nous rendre compte $\mathrm{du}$ savoir-faire $\mathrm{du}$ pêcheur à la ligne ou du ramasseur de champignons? Nous pouvons certes (nous devons) décrire leur matériel et leurs gestes. Mais nous savons bien qu'il ne suffit pas d'avoir le même matériel et de faire les mêmes gestes pour obtenir les mêmes résultats. Il y faut une expérience des lieux et des temps, des choses et des êtres, qui ne s'acquiert qu'au terme d'un apprentissage souvent long, et qui ne $s^{\prime}$ exprime guère ou pas du tout. Soit que les intéressés s'y refusent; c'est encore le cas le plus simple. Soit plus souvent qu'ils en soient incapables - et si nous faisons nous-même l'effort de passer par le même apprentissage, ce sera souvent pour nous apercevoir que nous aussi, nous sommes incapables d'expliciter l'efficacité que nous avons acquise. Et il ne faudrait pas croire que c'est dans la complexité de ces activités "naturalistes", si on peut dire, que sont la pêche ou la chasse, que gît toute la difficulté. Car c'est peut-être dans certaines tâches très simples, purement machinales, que les limites de l'explicitation apparaissent avec le plus de netteté. "Après un siècle de recherches, nous ne savons toujours pas pourquoi les dactylographes professionnels peuvent taper aussi vite» nous dit un psychologue (Salthouse 1984). Et s'il est vrai qu'il faille plusieurs mois pour apprendre à «limer droit» (c'est-àdire en produisant une surface rigoureusement plane), il est clair que la simple description de l'outil et du geste ne nous aide guère à comprendre pourquoi. De toute évidence, on ne peut rendre compte de l'habileté de l'ajusteur (si on le peut) $q^{\prime}{ }^{\prime}$ en termes neuro-psychologiques. Il faut ajouter cependant qu'il semble y avoir du non-explicitable absolument à tous les niveaux dans les activités techniques, et qu'on ne puisse l'enfermer dans des termes d'ailleurs bien vagues comme «habileté», "automatismes», "sixième sens», etc. "Les experts ne savent pas ce qu'ils savent», telle est la formule employée par un chercheur travaillant sur l'informatisation des tâches de conception appartenant aux ingénieurs (Fouet 1985). Ce qui oblige l'informaticien qui cherche à «extraire» leur savoir à proposer une solution quelconque pour obtenir leurs critiques, et parvenir ainsi de correction en correction au but final. Le parallélisme avec la situation d'apprentissage par «coups de pied au cul» que décrivent Delbos et Jorion (1984) est tout à fait évident. L'erreur de ces auteurs est simplement d'avoir cru que cette méthode n'est pas une transmission de savoir, alors qu'elle en est au contraire une des formes les plus importantes et les plus générales (même à l'école).

Ce n'est pas ici le lieu de développer ce sujet. Retenons seulement que dans 
toute activité technique, il existe une part non explicitable, même pour qui disposerait de tous les moyens d'investigation qu'offre la science actuelle. Or comme un chercheur donné, même associé à d'autres, est loin de disposer de l'ensemble de ces moyens, voire de connaître leur existence, il suit que la part non explicitable est beaucoup plus grande, dans la réalité de chaque recherche, qu'elle ne l'est en théorie. Souvent, d'ailleurs, ce sont des raisons beaucoup plus simples, on est tenté de dire enfantines, qui font qu'un chercheur ne voit pas ce qui se passe sous ses yeux. Voici, rapidement, quelques exemples usuels de non-perception ou de nonprise en compte de techniques:

- on ne les «voit» pas: la marche à pied et la plupart des habitudes corporelles (malgré Mauss), mais aussi de nombreuses techniques du quotidien (savoirvivre: Evleth 1980);

- on les voit, mais on ne les regarde pas: le pilage du mil en Afrique (il en est question dans quantité de monographies, mais l'activité elle-même n'est pratiquement jamais observée de près: Bril 1983);

- idem, mais parce le chercheur ne voit pas le rapport entre la technique en question et la problématique de sa recherche; - idem, enfin, parce qu'aux yeux des gens eux-mêmes, ce qu'il y a de proprement technique dans leurs activités n'est pas important.

Les deux premiers points renvoient à l'obstacle bien connu de la familiarité. Obstacle que seule une heuristique de l'étonnement peut apprendre à surmonter. Heuristique volontaire, comme l'ethnologie exotique classique, mais aussi involontaire, comme dans cent situations différentes de la vie courante que les ethnologues devraient apprendre peut-être à mieux utiliser.

Le troisième point renvoie à la nécessité de recherches comparatives, à la formation initiale des chercheurs, et à l'organisation $\mathrm{du}$ travail scientifique. C'est sur ce point, sans doute, que l'impact des mesures politiques et administratives est le plus grand.

Le quatrième point touche au vieux problème du rapport entre choix théoriques et observation des faits. La monographie dite à tiroirs est presque unanimement condamnée de nos jours. Elle avait pourtant les avantages d'une certaine sagesse théorique, consistant à admettre que ce n'était pas parce qu'on ne voyait pas tel rapport que ce rapport n'existait pas. On avait aussi la prudence de penser que les théories changent, et qu'il ne faut pas s'en remettre à elles seules du choix des faits à retenir. Les monographies axées sur une problématique précise expriment sans doute une "plus haute ambition» (Delbos et Jorion 1984: 45), et sont pour cette raison plus séduisantes, plus brillantes. Elles sont aussi plus contestables, dans la mesure où l'auteur se croyant en possession de moyens sûrs de juger de la pertinence des faits que lui offre son terrain, le risque de tautologie ou de biais dans ses conclusions devient très grand (Sperber 1982). Sans parler du risque beaucoup plus banal de laisser passer ainsi des occasions d'observer des faits qui ne se reproduiront plus. Quoi qu'il en soit, il est symptomatique sans doute que pour ce qui concerne les techniques agricoles dans le monde (ce qui correspond à mes recherches personnelles), les anciennes monographies, à tiroirs ou pas, soient une source beaucoup plus riche 
que, par exemple, les travaux plus récents $\mathrm{d}$ 'anthropologie économique.

Le cinquième et dernier point renvoie à des différences de conception sur ce que doit être le but même de la recherche anthropologique. Si en effet on admet que ce but est essentiellement d'élucider la vision $\mathrm{du}$ monde et d'eux-mêmes qu'ont les gens - une anthropologie interprétative - alors il est logique de ne pas prêter aux activités techniques plus d'intérêt que ne le font les gens eux-mêmes, c'est-à-dire quelquefois très peu (Barley 1983). Mais cette conception revient à admettre que l'idéologie et le symbolique «expliquent» les comportements réels, ce qui est pour le moins critiquable, et de plus en plus critiqué (Sperber 1982, Binford 1987, Keesing 1987).

J'ai conscience que cet avant-propos a été beaucoup trop long. J'espère toutefois qu'on voudra bien en retenir deux conclusions. la première est que la recherche sur les techniques se heurte à des difficultés graves et multiples dont certaines au moins lui sont propres, et que si la communauté scientifique (universitaire) n'accepte pas de faire un effort particulier pour les résoudre, la bonne volonté et même l'enthousiasme de tous ceux qui œuvrent à la sauvegarde et à la valorisation de ce patrimoine risquent de s'éteindre. La seconde est que toutes ces difficultés s'enracinent au cœur même des débats les plus actuels et les plus fondamentaux sur ce qu'est et sur ce que doit être l'anthropologie. Et il n'y a nul hasard en cela. Tous ceux qui depuis Diderot se sont penchés avec un minimum d'attention sur la question sont toujours arrivés à la conclusion que la technologie est une science humaine à part entière. Ce qui signifie que décrire un tire-bouchon est une tâche qui relève pleinement de l'anthropologie. C'est cela qu'il faut parvenir à faire admettre à l'ensemble du milieu universitaire.

Compte tenu de toutes ces remarques, il a paru commode d'organiser le contenu de ce rapport en quatre rubriques, qui sont les suivantes:

- les techniques et la technographie;

- savoirs, pratiques, tâches, apprentissage;

- le groupe social comme lieu de production simultanée de l'efficacité matérielle, du sens, et de l'identité;

- culture technique et patrimoine.

\section{Les techniques et la technographie}

Le terme technographie n'est pas d'usage courant. Mais il convient trop bien pour désigner ce dont il est question ici - la description des techniques par les moyens classiques de l'écrit, du dessin et des autres procédés graphiques - pour que nous nous en privions. Toutes les sociétés à écriture ont produit une littérature technographique plus ou moins importante. Dans l'Europe post-romaine, cette littérature remonte au $\mathrm{xx}^{\mathrm{e}}$ siècle, et prend un essor considérable aux $x^{\mathrm{e}}$ et Xvi ${ }^{\mathrm{e}}$ siècles. Mais c'est en 1750-1770, avec L'Encyclopédie et les Descriptions de l'Académie des Sciences, que la technographie reçoit ses lettres de noblesse. On a cent fois cité les pages célèbres dans lesquelles D'Alembert et Diderot exposent, 
dans des termes restés parfaitement actuels, les buts, les méthodes, les difficultés, et les limites de leur entreprise (e.g. Cornu 1984).

Depuis le $\mathrm{XVIII}^{\mathrm{e}}$ siècle, cependant, le développement industriel a été tel que l'entreprise technographique a dû restreindre son objet.

Diderot, ses émules et ses successeurs (notamment les technologues allemands, cf. Sebestik 1983) voulaient décrire les techniques de leur temps, pour en donner connaissance au public cultivé. Définie dans les mêmes termes, leur entreprise n'est pas transposable aujourd'hui. Et ce qui est grave, c'est que nous n'avons pas de solution de rechange. Le public, en gros, n'a accès aux techniques que par le canal de la vulgarisation scientifique, dont les inconvénients ont été mis en relief, entre autres, par P. Roqueplo (1974). L'enseignement, quant à lui, ne fait pratiquement aucune place aux techniques (en dehors des filières strictement professionnelles). Si bien que la «culture technique» de nos contemporains est peut-être plus faible que jamais, alors même que le monde dans lequel nous vivons est plus techniquement construit qu'il ne l'a jamais été (on a parlé de «techno-nature», de "règne machinal», etc.). la prise de conscience de ce paradoxe a conduit, vers 1976 ou 1977, à la création d'un «Groupe de recherches ethnotechnologiques» au Ministère de l'Industrie (P. Roqueplo, T. Gaudin, J. Perriault, A. Staropoli, R. Jaulin, entre autres). Ce groupe a été actif jusque vers 1981-1982. Il a publié en 1981 un Manifeste pour le développement de la culture technique préfacé par A. Leroi-Gourhan. Depuis lors, les réalisations en faveur de la culture technique se sont multipliées, ce qui est assurément un fait très positif. Mais peut-on considérer le problème de fond comme résolu pour autant? Ce n'est pas pour rien que les fondateurs du groupe «ethno-technologie», qui n'étaient pas ethnologues, avaient choisi cet intitulé. C'est parce qu'ils sentaient que les moyens d'une véritable connaissance «culturelle» des techniques n'existaient pas, et parce qu'ils espéraient que le point de vue ethnologique pouvait les aider dans cette recherche. Leur attente n'a pas été vraiment satisfaite, en partie pour des raisons circonstancielles, mais en partie aussi pour des raisons plus profondes. Peut-être l'ethnologie des techniques a-t-elle encore besoin que son objet soit «autre », et n'est-elle pas encore capable de retourner son regard sur «soi». Peut-être aussi la connaissance culturelle des techniques implique-t-elle par nature un regard plus historique, et ce serait alors sa focalisation sur l'actuel qui aurait conduit le groupe à cet échec partiel. Mais quelles que soient les explications, il vaut mieux accepter le fait pour ce qu'il est: tout se passe en effet comme si la technographie à la Diderot ou à la Leroi-Gourhan (c'est substantiellement la même) ne pouvait prendre utilement en compte aujourd'hui que des techniques exotiques, disparues ou en voie de disparition, c'est-à-dire dans tous les cas inactuelles; comme si autrement dit la technographie n'était possible que comme archéologie. Certains s'insurgeront sans doute contre cette affirmation. Mais je puis dire que tous les documents que j'ai lus pour préparer ce rapport le confirment pleinement. Qu'y-a-t-il de honteux à cela, d'ailleurs? Ce n'est que dans les discours d'inauguration qu'il est important de se dire 
«tournés vers l'avenir». Et si c'est bien pour de vraies raisons que la technologie se rattache à l'archéologie, mieux vaut, encore une fois, accepter le fait et en tirer les conséquences, plutôt que de s'épuiser en vains efforts pour le contrecarrer ou le dissimuler.

Il se vérifie, du reste, que les domaines les mieux structurés de la recherche sont ceux où l'archéologie joue un rôle important; les activités navales (en mer et en rivière) en sont peut-être l'exemple le plus démonstratif. On trouverait difficilement aujourd'hui, me semble-t-il, un secteur bénéficiant de plus d'atouts, notamment en ce qui concerne:

- la coopération entre disciplines (ethnologie, archéologie, histoire, etc.),

- la coopération entre statuts par rapport à la recherche (universitaires et personnel muséal, collectionneurs, informateurs, érudits, etc.),

- l'appui d'un public nombreux et compétent (grâce en partie au succès de la navigation de plaisance), qui rend possible l'existence d'une revue comme Le Chasse Marée, ou d'une émission de télévision comme Thalassa.

Une notion me paraît propre à illustrer de façon particulièrement claire cet état structuré d'un secteur de recherche, c'est celle de découverte sensationnelle, de scoop si on veut bien me passer cet emprunt à l'argot des journalistes. Mais un emprunt qui justifie l'écho que donne parfois la grande presse à de telles découvertes. Une des plus récentes est celle d'un vaisseau hollandais, le Mauritius, qui au retour d'un voyage de plusieurs années en Extrême-Orient, fit naufrage au large du Gabon en 1609 (Miquel 1987). Or c'est pour des raisons bien précises que cette découverte est un scoop. Il se trouve que la construction navale et les navires européens de cette époque sont très mal connus. Il se trouve aussi que le Mauritius ramenait dans ses cales un chargement de lingots de zinc en provenance de Chine qui est une aubaine pour les historiens de la métallurgie. Tout cela concourt à faire de cette découverte un événement international. Mais des découvertes beaucoup plus modestes conservent le même caractère sensationnel, à leur échelle. La découverte de la dernière gribane de la Basse-Seine à la fin des années 1970 (Morel 1984: A0 81.06) n'a certes pas fait les gros titres de la presse nationale. Mais elle témoigne de la même réaction et de la même structuration du milieu de la recherche que celle du Mauritius.

Il ne manque pas de scoops dans les documents à caractère peu ou prou technographique qui figurent dans les dossiers de la Mission du Patrimoine. Outre la dernière gribane, je citerai à titre d'exemples:

- les vestiges de plusieurs fours à goudron, d'un modèle non décrit dans la littérature, découverts sur plusieurs sites de la Teste et à Biscarosse (Aufan: E A0 82.95);

- le dernier «martineur», héritier d'une tradition de métallurgie du cuivre qui remonte au $\mathrm{XVII}^{\mathrm{e}}$ siècle, à Dorfort, Tarn (Chapuis: 86 MP 81);

- une technique unique en France, la fabrication de pinces de précision dites «entrepassées » à Montecheroux, Doubs (Hell: 87 PC 196);

- des métiers à filer la laine dits "renvideurs», exigeant des compétences particulièrement élevées, à Fourmies, Nord (Goujard: 87 NPC 207), etc.

Inutile d'allonger cette liste. Il suffit qu'on voie de quoi il s'agit. Et ce qui 
nous intéresse ici, c'est que l'existence de scoops paraît bien être l'indicateur d'un certain état de maturité atteint par un secteur de recherche. Elle signifie, au moins à première vue, qu'un niveau minimum de connaissances y est assez bien distribué pour que les participants soient à peu près d'accord sur l'inventaire de ce qui est connu et de ce qui ne l'est pas, et sur l'état des questions. Il est clair que, dans ces conditions, la formulation des projets et l'évaluation des résultats peuvent prendre une netteté, un caractère d'évidence qu'ils n'auront pas ailleurs. On peut admettre aussi que dans de tels secteurs, il est possible d'identifier rapidement, un projet étant donné, le ou les experts susceptibles de donner immédiatement un avis compétent. Et on pourrait imaginer que le Conseil du Patrimoine se dote d'un fichier de ces experts au fur et à mesure de ses consultations extérieures.

Cela dit, tous les secteurs de la recherche technographique sont loin d'être arrivés au même état de maturité. À côté de ceux qui bénéficient depuis des générations d'un prestige et d'une visibilité sociale qui ne se démentent pas (navigation, métallurgie, architecture, textile, arts du feu, etc.), il y a les éternels parents pauvres (techniques ménagères, industries alimentaires...). Cela tient au caractère idéologique de la distinction que fait notre société entre ce qui est technique et ce qui ne l'est pas. Cela peut aussi tenir à des déséquilibres comme celui que dénonce G. Ribeill (1985: E 83.81) dans le secteur de la culture ferroviaire: trop de passionnés exclusifs de la locomotive à vapeur, trop peu de vrais chercheurs. De plus, on constate à l'intérieur de chaque secteur des inégalités de traitement étonnantes. L'architecture rurale dite traditionnelle a été étudiée depuis longtemps; on vient seulement de prendre conscience qu'il existait une tradition savante de construction des bâtiments agricoles à usage technique, remontant au début du XIX ${ }^{\mathrm{e}}$ siècle. Et dans un domaine voisin: combien de travaux récents sur le cheval (excellents, d'ailleurs), et combien sur le bœuf de travail?

Pour corriger autant que faire se peut ce genre de déséquilibre, il semble que la technographie devrait faire l'objet du même effort de synthèse que celui qui a été fait, par exemple, en botanique systématique. C'est le seul moyen d'éviter que les chercheurs se bousculent sur certains terrains et en désertent d'autres, et c'est le seul moyen d'éviter la répétition des mêmes descriptions à côté de la perpétuation des mêmes lacunes. La perspective d'une espèce $d$ 'herbier de référence pour les techniques peut paraître bizarre ou peu enthousiasmante, ou encore irréalisable. Mais y a-t-il d'autres moyens d'organiser les recherches dans un domaine où tout passe par une certaine érudition? Il s'agit, en somme, d'organiser celle-ci. Le premier pas pourrait être ce fichier d'experts auquel il vient d'être fait allusion. Le second pourrait être la généralisation d'études comme celle de G. Ribeill, permettant de porter un diagnostic sur l'état de maturité des différents secteurs et sur leurs déséquilibres internes. Un troisième pas, enfin, pourrait être de constituer progressivement un patrimoine de référence, qui serait constitué d'ensembles techniques assez complets et assez bien documentés pour pouvoir être utilisés comme descriptions-types. Non pas que ces descriptions doivent être conçues comme des modèles à imiter, ni que les ensembles décrits doivent être particulièrement 
«représentatifs»: en géométrie, l'emplacement exact d'un système de coordonnées importe moins que son existence, c'est-à-dire le fait que c'est par rapport à ce système et à lui seul qu'on situe tous les autres points de l'espace. De telles descriptions de référence existent déjà sans doute, et la première chose à faire serait de vérifier leur existence et leur utilité avant d'aller plus loin.

Encore une fois, cependant, tout cela n'est qu'organisation de l'érudition. Or si la recherche est absolument nécessaire en technographie, elle ne suffit évidemment pas: nous savons tous qu'elle a ses limites, qui deviennent des dangers lorsqu'on se résigne à ne pas les franchir. Un de ces dangers est un certain ésotérisme. Ce n'est pas un hasard si les secteurs les plus développés de la recherche technographique sont aussi les plus autarciques. Ceux où la curiosité des chercheurs, comme si elle était canalisée, saturée par la multiplication des questions de détail, est la moins ouverte aux problématiques neuves. Tout se passe comme si l'érudition en arrivait à se stériliser elle-même, en quelque sorte. En technologie, c'est surtout sur le plan des méthodes et des concepts communs que cet ésotérisme est néfaste. Il faut bien reconnaître en effet que dans la pratique, les différents secteurs de recherche se sont développés dans un isolement réciproque guère moins marqué que celui des différentes branches dont ils s'occupent: les marins ne parlent guère plus avec les cultivateurs que les métallurgistes avec les brodeuses ou les mineurs avec les boulangers... Et tant qu'il en sera ainsi, la technologie en tant que science, et par conséquent la culture technique, ne pourront rester qu'à l'état de vœu pieux.

C'est sur ce point précis que l'ethnologie a un rôle éminent à jouer. À la fois de par le point de vue qu'elle représente dans l'ensemble des sciences humaines, et parce que de tout temps, les ethnologues ont été confrontés à la tâche terriblement difficile de rendre compte de toutes les techniques d'un groupe donné. L'œuvre d'A. Leroi-Gourhan est paradigmatique de cette ambition presque démesurée. Mais en même temps, cette œuvre nous pose un problème. Car les concepts proposés par Leroi-Gourhan - ceux de tendance et de fait, par exemple, ou ceux qui lui ont servi à élaborer son tableau des percussions - datent aujourd'hui de quarante à cinquante ans. Doit-on continuer à les considérer comme une base théorique immuable et indépassable? Un lecteur non prévenu des contributions présentées en hommage à LeroiGourhan dans le $n^{\circ} 7$ de Terrain serait conduit à le penser. Je ne peux pas cacher ici ma conviction qu'il n'en est rien, et qu'il est devenu nécessaire de soumettre l'œuvre théorique de Leroi-Gourhan à une critique approfondie. Ce sera une discussion difficile, non seulement sur le plan scientifique, mais parce qu'elle est chargée d'affectivité. Pour certains de ceux qui se réclament de son enseignement, en effet, toute remise en cause des idées du "patron" apparaît comme presque sacrilège. Cette réaction finira bien par s'estomper. Mais pour l'instant, elle a sur les recherches technologiques l'effet paralysant de tous les dogmatismes. Il faudra bien les surmonter si on veut que la technologie sorte de la situation peu prometteuse qui est si souvent et si rituellement déplorée. 


\section{Savoirs, pratiques, tâches, apprentissage}

La technographie a pour objet la transformation que l'homme fait subir à la nature, à la matière. Aussi son point de vue est-il classiquement celui de la matière, c'est-à-dire celui des différents états par lesquels elle doit passer pour, de matériau brut, devenir produit fini. C'est dans les activités artisanales que ce point de vue s'impose de la façon la plus évidente: un des exemples les plus parlants est assurément celui qui a été repris par Bertrand Gille dans son Histoire des techniques, la fabrication d'un sabot. Mais l'exemple de la chapellerie à Chazelles-sur-Lyon (10 82.16) est tout aussi démonstratif; d'autant plus qu'en l'espèce, il s'est produit depuis le XviI ${ }^{e}$ siècle une division de plus en plus poussée du travail, qui a abouti à ce que chaque étape du processus devienne une spécialité professionnelle distincte. Le fait que l'organisation du travail s'y fasse en fonction de telles «filières» identifiées par les transformations successives de la matière est du reste une des caractéristiques de l'artisanat et de la plupart des industries qui en sont issues. Il serait erroné de penser, toutefois, que c'est seulement dans les cas où la division du travail la rend pratiquement évidente que l'approche «filière» se justifie. Quelle que soit l'activité que l'on cherche à comprendre, repérer les étapes successives dans la transformation de la matière (même s'il s'agit de simples déplacements) est toujours la première chose à faire. Car c'est bien cette transformation qui est le but du travail, qui lui donne son sens. Tel est, s'il est loin d'être le seul, l'objectif premier de la recherche technographique - un objectif bien moins facile à atteindre qu'il n'y paraît, une bonne partie des discussions de méthode auxquelles je viens de faire allusion vient de là.

Delbos et Jorion (1984: 11) appellent savoir procédural cette connaissance des étapes d'un processus productif, telle qu'elle peut être «abstraite de l'observation d'une pratique». La formule comble un vide, et mérite à mon avis d'être retenue, une fois débarrassée des ambiguïtés et des contradictions que ses auteurs y ont laissées². Ceci posé, il va de soi que le savoir procédural n'est pas le tout de la technique, et que la technique n'est pas le tout de la pratique: une évidence, à énoncer les choses ainsi, mais où la confusion apparaît vite dès lors qu'on entre un peu dans le détail.

On aimerait en effet pouvoir disposer d'une catégorisation des savoirs un peu moins superficielle que celle dont nous nous servons habituellement. Car il faut bien reconnaître que nous sommes loin du compte. On parle par exemple de savoirs naturalistes; la catégorie est utile, mais basée sur une idée de la nature propre à la culture savante de l'Occident moderne, et on ne peut donc pas la projeter sans danger chez des sujets appartenant à d'autres cultures. Les travaux de Brien A. Meilleur en Savoie ont bien montré, d'ailleurs, tout ce que ces savoirs doivent à la pratique. On oppose souvent connaissance et savoir-faire, et c'est une opposition valide, utile, et même indispensable à bien des égards. Mais nous venons de voir que le savoir procédural est très exactement connaissance d'un savoir-faire; connaissance qui n'existe pas seulement à l'état explicite chez le technographe ou à 
l'état implicite chez le praticien, mais qui est le fait de tous ceux qui ont une position de direction dans un ensemble d'activités hiérarchisées (architecte, chef d'orchestre, général, ingénieur des méthodes...). Lorsqu'au savoir procédural vient s'ajouter le minimum d'habiletés nécessaires à l'exécution correcte de la tâche, on parle de compétence. Et on parle de performance lorsque ces habiletés atteignent le niveau d'efficience exigé par les normes sociales en vigueur; on pourrait encore parler de virtuosité lorsqu'elles les dépassent. Mais faute de savoir ce que sont exactement ces habiletés, tout cela reste très empirique. Le terme même d'habileté évoque ceux d'entraînement, d'automatisme, de réflexe conditionné..., mais cet enrichissement du vocabulaire n'éclaircit guère les choses. Il y a, d'ailleurs, des habiletés qui sont tout le contraire d'automatismes, mais qui sont de véritables entraînements à la créativité. Sans parler de la virtuosité musicale, de la créativité artistique ou du chef d'œuvre du compagnon, où cela est évident, on trouve des exemples de créativité tout aussi remarquables dans des activités considérées comme banales ou peu qualifiées. C'est le cas du trait en charpente, qui toutefois est encore un des artisanats les plus savants (les charpentiers ont des livres, et ils les lisent (Calame 1983, Bardagot et Sabatier A0 82.57). C'est le cas de la réalisation "ordinaire» de tissus décorés à l'aide de moyens techniques rudimentaires, qui fait appel, semble-t-il, à des capacités mathématiques très élaborées (travaux de MarieNoëlle Chamoux, Sophie Desrosiers, Monique Lévi-Strauss et Aurore SagotOrtega) ${ }^{3}$. C'est le cas surtout de tous ceux, de l'agriculteur à la ménagère, qui ont à programmer des activités nombreuses et complexes en fonction de critères encore plus nombreux et complexes, ou qui ont à trouver des solutions toujours originales à des situations qui ne se reproduisent jamais: ce sont d'autres facultés mathématiques, de nature combinatoire, qui interviennent (Darré 1977, Salmona et al. 1980). La question, pour nous, est: que faire de tout cela? Où situer une recherche sur les savoirs et les savoir-faire? Sur quoi nous appuyer? Comment nous orienter?

Personne n'a de réponse prête à cette question. Je soulignerai, pour ma part, deux directions de progrès possibles: explorer les ressources de l'interdisciplinarité, et tirer parti des situations de confrontation entre savoirs d'origines différentes.

\section{Explorer les ressources de l'interdisciplinarité}

Ce qui rend cette exploration indispensable, me semble-t-il, c'est que l'ethnologie réduite à ses propres moyens n'a pas actuellement de problématique satisfaisante à proposer pour l'étude des savoirs et savoir-faire. Cette affirmation choquera peut-être certains. Tout ce que j'ai pu lire dans les dossiers de la Mission du Patrimoine ou ailleurs m'a pourtant confirmé dans cette opinion. En particulier, tout ce qui touche l'apprentissage ou la «transmission des savoirs» est d'une grande banalité, et se réduit en général à une périphrase de ce qu'écrivait Herskovits il y a près de quarante ans sur le processus d'inculturation. Mais je ne crois pas qu'il faille en faire grief aux auteurs, même si certains réussissent à déguiser cette banalité en recourant à la littérature ou au paradoxe. L'ethnologue localise des savoirs dans les filières matérielles, 
il les désigne, il les admire, et les célèbre éventuellement, il fait parfois l'effort de les acquérir, et tout cela est nécessaire à bien des titres. Mais il ne les décrit ni ne les analyse, parce que, selon toute vraisemblance, il n'en a pas les moyens. Ces moyens, s'ils existent, c'est donc vers $d^{\prime}$ autres disciplines qu'il faut se tourner pour les trouver.

On pense immédiatement, bien sûr, à la psychologie et aux sciences cognitives. Mais deux difficultés s'y présentent tout de suite de notre point de vue: celle de s'orienter dans un complexe de spécialités touffu et changeant (mais l'ethnologie ne doit guère offrir au profane un tableau plus clair), et celle, surtout, de la différence de langage. Nous nous intéressons à des savoir-faire, à des savoirs techniques. Or c'est une catégorie qui n'apparaît guère en tant que telle dans les paradigmes des psychologues.

Je crois, toutefois, qu'il ne faut pas s'arrêter à ces difficultés, et qu'il y a au moins deux régions de contact où de réelles perspectives de progrès sont ouvertes.

La première est la psychologie interculturelle. Cette branche récente, mais en plein développement, se propose précisément de rendre compte des savoirs et de leur acquisition sans les dissocier de leur contexte culturel propre (ce qui avait été reproché à la psychologie traditionnelle). Les travaux de Blandine Bril s'y rattachent (Bril et Joubert 1986: A0 83.100). Pour l'instant, toutefois, l'approche «microscopique» de B. Bril dans l'étude des gestes, et celle, nettement plus «macroscopique» des ethnologues ne parviennent pas à se rejoindre. On a un peu l'impression d'un phonéticien qui étudierait les sons d'une langue à l'aide d'appareils extrêmement précis, mais sans que personne ne soit en mesure de rien lui dire sur le sens que ces sons véhiculent. Quoi qu'il en soit, ce hiatus pose, me semble-t-il, un problème très important, et qui devra prendre place dans la discussion évoquée ci-dessus (p. 136).

La seconde région de contact est celle de la psychologie du travail et de l'ergonomie. Peut-être est-ce le caractère "appliqué» de ces deux disciplines qui en a jusqu'ici écarté les ethnologues. Mais les choses peuvent et doivent changer. Les ergonomes ont officiellement «découvert» Leroi-Gourhan et l'ethnologie il y a quelques années (Leplat et Pailhous 1981). C'est maintenant aux ethnologues à «découvrir» l'ergonomie. Si ce n'était d'ailleurs que dans la perspective traditionnelle d'une meilleure connaissance des techniques du corps, l'apport de l'ergonomie, en particulier de l'ergonomie exotique, serait déjà irremplaçable ${ }^{4}$.

En France, c'est, semble-t-il, dans le domaine du travail agricole que le dialogue a commencé à s'établir le plus tôt. Il faut citer à cet égard les travaux de la psychologue Michèle Salmona dès 1972, et le colloque de Rodez, «Ergonomie et amélioration des conditions de travail en agriculture», en 1977 (cf. Études rurales 1977, 67: 93-96), auquel participèrent déjà au moins une douzaine d'ethnologues ou de sociologues en titre.

Un des intérêts de l'ergonomie est de représenter un axe de recherche transversal à celui de la technographie, en quelque sorte. Celle-ci, on a vu pourquoi, privilégie en général une démarche descriptive qui suit la matière dans les étapes successives de sa transformation: appelons cela le point de vue filière. L'ergonomie s'efforce au contraire de suivre 
le travailleur dans les étapes successives (ou simultanées) de son activité, qu'elles se rattachent ou non à une même filière: j'appellerai cela le point de vue tâche. Il est clair que les deux points de vue sont complémentaires, et aussi indispensables l'un que l'autre.

Comme exemple d'approche en termes de tâche, je citerai le travail récent de Nicourt et Filippi (1987). La méthode que préconisent ces auteurs implique une étude en deux temps. Premier temps, ils observent et enregistrent l'activité de la ou des personnes considérées avec les moyens adéquats, et en font une analyse. Deuxième temps, ils soumettent cette analyse à la ou les personnes observées, pour recueillir auprès d'elles leur propre analyse de ce qu'elles ont fait. Le parallélisme avec certaines méthodes d'enquête linguistique est frappant (Haudricourt, communication personnelle). Il me semble en tout cas qu'il y a là une voie très intéressante pour accéder aux savoirs, et qui pourrait permettre de sortir des banalités habituelles que l'on répète à leur sujet. (On observera que dans tout cela, les termes "étique» et "émique", d'un emploi maintenant si courant dans l'anthropologie cognitive anglo-saxonne, n'apparaissent pas.)

L'ergonomie n'est certainement pas la seule discipline à pratiquer l'approche en terme de tâche. Un historique sérieux de la question, que je ne suis pas compétent pour faire, produirait sans aucun doute de nombreux antécédents dans d'autres disciplines, y compris l'ethnologie et la sociologie. Il faut aujourd'hui leur ajouter l'économie et la géographie. Il se trouve maintenant des économistes pour s'intéresser aux faits de vie quotidienne que l'économie classique consi- dérait comme hors de son domaine, parce qu'ils espèrent y trouver les explications qui leur manquent à certains phénomènes généraux: $c^{\prime}$ est de leur part un recours à l'ethnographie, même s'il reste informulé (Gershumy 1987). Quant aux géographes, il s'agit d'une école suédoise de "géographes du temps", qui s'attachent à décrire en «micro-détail» la structure spatio-temporelle des activités des personnes. Je ne connais cette école que par ce qu'en dit Gershuny.

\section{Tirer parti des confrontations entre savoirs}

Un des aspects de la situation de l'ethnologue sur son terrain est qu'il se trouve confronté, étant adulte, à une culture autre que sa culture "maternelle», celle qui lui a été inculquée dans son enfance et sa jeunesse. Cette heuristique de la différence et de l'étonnement a toujours été une des grandes sources d'interrogation sur les choses humaines. La philosophie s'en est abondamment servie, et le tourisme, à l'origine, n'était pas autre chose (y compris naturellement le tour de France compagnonnique). Or, il existe, dans la vie courante d'aujourd'hui, d'innombrables «terrains» de confrontation culturelle, qui sont évidemment involontaires pour les partenaires qui s'y trouvent en présence, mais où ceux-ci se trouvent forcés, pour résoudre les malentendus ou les conflits qui les opposent, à expliciter certains éléments de leurs cultures respectives. Chacune de ces explicitations est alors, si un chercheur se trouve là pour la recueillir, une voie d'accès particulièrement profitable aux deux cultures en présence. Dans le domaine des savoirs, cette voie d'accès 
est tellement profitable qu'on serait tenté de la qualifier de royale.

Quelques chercheurs s'y sont déjà engagés, par le biais des néo-ruraux par exemple, ces citadins qui «apprennent» à vivre et à travailler à la campagne à un âge beaucoup plus avancé que d'habitude (e.g. Luxereau 1986, Delbos et Jorion 1984: 218 sq.). Et je suppose que les recherches effectuées en réponse à l'appel d'offres «France, société pluri-ethnique", que je n'ai pas dépouillées, offriraient $d$ 'autres exemples. Je voudrais seulement suggérer que ces "terrains» au second degré, pour ainsi dire, soient plus systématiquement identifiés et étudiés dans la perspective précise qui est la nôtre ici. Et je voudrais appuyer cette suggestion en évoquant plus particulièrement le cas sur lequel je suis le mieux informé, celui de l'agriculture.

C'est en 1974 que M. Salmona interprétait en termes d'opposition entre culture prescrite et culture spontanée le malentendu persistant qui séparait, dans la vulgarisation technique et économique, ceux qui étaient censés produire un savoir, et ceux qui étaient censés le recevoir et l'appliquer - agronomes et techniciens d'un côté, agriculteurs de l'autre. Dans l'absolu, ces qualificatifs "prescrite» et «spontanée» ne convenaient évidemment pas, puisque toute culture est à la fois prescrite (imposée aux membres du groupe) et spontanée (produite par eux); il s'agissait en fait, tout simplement, de culture dominante et de culture dominée. Mais si les qualificatifs étaient impropres, l'idée d'opposition qu'ils exprimaient ne l'était pas, et en la déguisant un peu, peut-être aidèrent-ils à la faire plus facilement «passer». Car c'est là qu'était tout le pro- blème. Pour un observateur non engagé, le décalage entre la façon de dire et de penser des agronomes et des paysans, sur les mêmes objets, est presque une évidence. Mais c'était une évidence inutile, en quelque sorte, puisque tout projet de recherche s'en réclamant aurait couru le risque d'être immédiatement rejeté ${ }^{\text {. }}$ Pour la première fois, des décennies d'échecs dans la vulgarisation, et d'impuissance de la sociologie et de la psychologie classiques à en rendre compte, forçaient enfin cette évidence à devenir visible.

Depuis lors, pas mal d'eau a coulé sous les ponts. J.-P. Darré rend compte de façon très vivante des aspects épistémologiques de l'évolution des idées dans l'introduction restée malheureusement inédite de sa thèse (1982: 6-39). Côté agronomes, il existe désormais une minorité active pour considérer qu'il existe des savoirs paysans, qu'il vaut la peine de les comprendre, et que par conséquent l'ethnologie est autre chose qu'une manière originale de perdre son temps. Il n'est pas question de rendre compte ici de tout ce mouvement, buissonnant et complexe. Ce que je voudrais souligner, c'est l'importance cardinale de la situation dans la problématique de ces recherches. Il me paraît tout à fait vain d'entreprendre aujourd'hui une recherche en vue d'expliciter le contenu conceptuel de savoirs paysans ${ }^{6}$, sans prendre part, d'une façon ou d'une autre, et volontairement ou non, à cette situation de confrontation de savoirs que je viens d'évoquer. Ce n'est pas un hasard si des auteurs comme $\mathrm{M}$. Salmona, J.-P. Darré et leurs émules se sont tous mis à la recherche sur le tard, après dix ou vingt ans de carrière dans les milieux para-agricoles. Ce long enra- 
cinement dans la situation leur a été nécessaire pour pouvoir mettre à jour les problèmes sur les lieux mêmes où ils se posent.

Tout se passe au fond comme si l'explicitation d'un savoir ne pouvait se faire que par la confrontation avec un autre savoir autrement structuré. D'où suivent, à mon avis, deux conséquences. La première est que le chercheur doit trouver une telle situation de confrontation, il ne peut pas la fabriquer (même en se faisant «apprenti», $j^{\prime}$ 'y reviens dans un instant). La seconde est qu'il ne peut $s^{\prime} y$ insérer sans être admis à le faire par les participants. Les conditions de cette admission varieront naturellement en fonction de la situation. Elles pourront être assez simples lorsqu'on s'adressera, par exemple, à certains néo-ruraux, ou au contraire à des agriculteurs âgés ayant travaillé dans des fermes en Allemagne pendant la dernière guerre (une très belle situation d'enquête que je ne peux me retenir de signaler au passage). Lorsqu'au contraire on voudra s'adresser à des agriculteurs «à part entière» si je puis dire, c'est-à-dire entièrement impliqués dans la production et pour faire une recherche sur les pratiques mêmes de cette production, les conditions d'admission seront beaucoup plus strictes. Il faudra, dans la plupart des cas, que l'ethnologue acquière une position professionnelle réelle, faisant de lui un des partenaires que l'agriculteur a l'habitude de rencontrer. On en revient au b.a.-ba de l'ethnologie participante. Mais un b.a.-ba qui implique bien davantage qu'une formation générale à l'ethnologie. Jusqu'ici on a surtout vu des professionnels se tourner vers l'ethnologie sur le tard, après quelques années de carrière. La question se pose de savoir si des chercheurs n'ayant suivi qu'un cursus universitaire normal en ethnologie peuvent faire la démarche inverse. Il ne me semble pas que la réponse soit évidente.

Je voudrais, à titre de complément, revenir brièvement sur le problème de l'apprentissage. J'ai parlé de banalité à ce sujet. Je voulais exprimer par là deux choses: l'impression de similitude et presque de monotonie qui se dégage des diverses descriptions, de l'allusion de quelques lignes au chapitre de vingt ou trente pages; et le peu de résultats apparents en ce qui concerne l'accès aux savoirs. Le premier point est en fait un acquis important, sur lequel il faudra revenir. Quant au second, Delbos et Jorion le confirment à leur manière, lorsqu'ils concluent qu'il n'y a pas transmission de savoir dans l'apprentissage, mais seulement transmission de travail. Cette proposition est à la fois un paradoxe (il y a bien transmission de savoir si on ne veut pas jouer sur les mots) et un subterfuge (elle permet d'évacuer le problème au lieu de le résoudre), mais elle a quelque chose de tout à fait vrai: la situation d'apprentissage n'est pas favorable à l'explicitation des savoirs. Et cela, parce que l'apprentissage n'est pas une situation de confrontation culturelle, comme celles qui ont été évoquées ci-dessus, mais au contraire un mode d'inculturation. L'apprenti y acquiert ses "pratiques maternelles», s'il est permis de s'exprimer ainsi. Mais il acquiert en même temps les traits de son identité et de sa personnalité, et il n'est donc pas en mesure de les considérer comme des objets extérieurs à lui.

Tout cela n'est pas pour dire que la situation d'apprentissage soit sans 
intérêt, bien au contraire. Mais si on ne veut pas que les récits d'apprentissage s'accumulent avec aussi peu de conséquences que tant de descriptions de forges, d'ateliers de sabotier ou d'abattages du cochon, il faut savoir ce qu'on y cherche. Les chercheurs paraissent dans l'ensemble impressionnés par les traits qui opposent l'apprentissage de l'ensei- gnement scolaire, ou plutôt à l'image assez simpliste que nombre d'entre eux semblent en avoir gardée. Il me semble qu'il faut sortir de cette problématique, et que pour ce faire, il faut avoir recours plus sérieusement aux sciences de l'éducation. J'ignore ce qu'elles ont produit sur ce sujet, mais il serait étonnant qu'elles n'aient rien produit du tout.

\section{Le groupe social comme lieu de production simultanée de l'efficacité, du sens et de l'identité}

Nous pouvons tous observer, depuis dix ou quinze ans, l'emploi croissant dans la vie courante d'un vocabulaire d'origine ethnologique. Le terme de culture, entre autres, connaît une fortune singulière. Que ce soit dans des discussions sur l'immigration ou la xénophobie n'a rien pour étonner. Mais qu'on parle aussi couramment de "culture de gouvernement» (que la gauche aurait acquise en 1981-1986) ou de "culture d'entreprise» (à propos de la dernière grève à la SNCF) est plus nouveau. On fait désormais l'«ethnographie» des états-majors des partis politiques (Schonfeld 1985) ou des laboratoires de recherche (Latour 1984), celle des groupes de pression, des grandes écoles, de certains quartiers urbains (le Sentier à Paris), etc., etc. C'est à une véritable ruée vers l'ethnologie qu'on assiste dans les sciences humaines et dans le milieu journalistique. Ruée qui a ceci de remarquable que les ethnologues en titre n'y participent guère, sans qu' on puisse être sûr que c'est seulement parce qu'ils sont trop peu nombreux. Pour la plupart, les participants n'ont aucun intérêt particulier pour les objets traditionnels de l'ethnologie, ils se bornent à lui emprunter les concepts et les idées dont ils ont besoin. Qu'est-ce que cela signifie?

Il semble qu'il y ait deux façons, l'une en termes très généraux, l'autre en posant des hypothèses beaucoup plus précises, de répondre à cette question.

En termes généraux, tout se passe comme si des disciplines de plus en plus nombreuses, de l'économie à la philosophie des sciences, étaient en train de s'apercevoir qu'il se passe quelque chose d'essentiel au niveau des "petits» groupes sociaux, ceux de l'ethnologie traditionnelle, et que c'est là qu'il faut aller chercher les explications que les théories et modèles classiques sont de plus en plus impuissants à fournir. Les travaux de J.-P. Darré, qui ont déjà été cités, sont un des meilleurs exemples de ce changement d'échelle. Je ne peux m'empêcher de leur associer ceux de Thomas S. Kuhn en histoire des sciences. La structure des révolutions scientifiques (1962-1972) était déjà d'une tonalité très 
ethnologique, quoi que de façon informulée. Avec «Scientific development and lexical change» (1984), la référence à l'ethnologie devient explicite: il y est question des différentes «tribus» du monde scientifique, des «croyances » qui identifient l'appartenance à une tribu et du langage spécifique dans lequel elles s'expriment, de la nécessité d'appartenir à une tribu et d'en parler la langue pour pouvoir en discuter les croyances, etc. En réalité, la similitude entre les faits décrits par Darré et ceux que décrit Kuhn est telle qu'on oublie facilement qu'il s'agit d'éleveurs de vaches dans un cas, et de physiciens ou de biologistes dans l'autre.

Ces deux exemples n'épuisent assurément pas l'immense sujet qu'est le recours aux concepts de l'ethnologie de la part des autres sciences sociales. L'histoire économique et sociale (l'histoire industrielle surtout) en offrirait quantité d'autres. L'intérêt des travaux de Kuhn et de Darré est qu'ils nous permettent de poser tout de suite une hypothèse plus précise, que j'énoncerai ainsi:

$1^{\mathrm{e}}$, une vie sociale normale nécessite que chaque personne acquière un minimum de pratiques matériellement et socialement efficaces;

$2^{\mathrm{e}}$, les savoirs (au sens large) qui soustendent ces pratiques ne peuvent être produits qu'au sein de groupes sociaux $d^{\prime}$ 'une certaine taille, ni trop petits ni trop grands;

$3^{e}$, pour exister, ces groupes doivent remplir des conditions générales: avoir une identité reconnaissable et reconnue, un minimum de cohésion interne, des procédures pour le règlement des conflits, pour le recrutement, l'initiation et l'intégration de nouveaux membres, etc.; $4^{\mathrm{e}}$, une de ces conditions d'existence est essentielle: chaque groupe doit équilibrer ses échanges avec l'extérieur; la façon dont il y parvient dépend de l'efficacité des savoirs qu'il produit, et de la façon dont il y parvient dépend sa position relative dans la société globale.

Devant cette hypothèse, la question est évidemment de savoir pourquoi il doit en être ainsi: pourquoi faut-il un groupe, et pas n'importe lequel, pour qu'il y ait production de savoirs efficaces? La réponse se trouve à mon avis dans les deux ouvrages déjà cités de Kuhn (1984) et de Darré (1985), mais il serait prétentieux de ma part de prétendre la résumer ici. Disons seulement que pour qu'il y ait comportement efficace chez l'homme, il faut qu'il y ait norme et sens, et que c'est dans le dialogue régulier, verbal ou non, entre membres d'un groupe limité, que normes et sens se construisent. Le groupe, en quelque sorte, apparaît comme le creuset où s'élaborent à la fois, et par le jeu même des interactions, l'efficacité, le sens, et l'identité. Le sens comme condition pour acquérir une efficacité, et l'identité comme condition pour accéder au sens.

Réglons tout de suite un point de vocabulaire. Le "groupe» dont nous parlons est-il homologue à ceux, de l'ethnie au lignage, dont traite l'ethnologie exotique, et sa «culture» est-elle l'équivalent de ce que l'anthropologie traditionnelle entend par là? Ou bien l'application de ces termes à des réalités de l'Europe moderne n'est-elle qu'une métaphore trompeuse?

Il me semble qu'il y a bien homologie, mais partielle. Car à la différence des groupements tels que tribus, clans ou lignages, il y a au moins deux plans 
sur lesquels notre «groupe» n'intervient pas, ou pas ordinairement: la production des enfants, et le politique. L'absence de ces fonctions est d'ailleurs un aspect qui n'est peut-être pas le moins intéressant de cette hypothèse, parce qu'elle permet de mieux sérier les problèmes. Dans des groupements entièrement autonomes, c'est-à-dire qui cumulent toutes les fonctions à la fois, il devient très difficile de démêler les relations réelles et les déterminations. Nos «groupes» permettent de mettre plus clairement en évidence les conditions de production de l'efficacité. Et à un échelon intermédiaire, il apparait des cas fort instructifs. Que sont les groupes de pression, en effet, sinon des groupes à la fois producteurs d'une efficacité, et qui cherchent à intervenir à leur profit sur le plan politique? À l'opposé, dans les sociétés paysannes traditionnelles, le «groupe» n'a pas d'autonomie politique, mais il a en charge la production des enfants: Delbos et Jorion montrent de façon très convaincante comment le groupe gère également cette production-là, en fonction des conditions d'efficacité qu'il doit remplir pour assurer sa continuité.

Quoi qu'il en soit, j'en suis venu à penser que si le recours à l'ethnologie a gagné tellement de terrain dans tous les milieux, scientifiques et autres, où on essaie de comprendre la société actuelle, c'est parce que l'importance des groupes de petites dimensions s'impose de plus en plus. Une importance qui tient au fait, me semble-t-il, que c'est au sein de tels groupes, et d'eux seulement, que l'efficacité, le sens et l'identité sont produits ensemble.

Reste à savoir à quoi ressemblent concrètement ces groupes, comment ils fonctionnent, quels sont leurs rapports avec l'extérieur, etc., et comment tout cela varie en fonction des diverses efficacités qui doivent être produites. On comprendra qu'il ne soit pas possible de poser ce genre de questions avec quelque précision ici, d'autant moins que, par exemple, une notion comme celle d'efficacité est loin d'être claire. Je voudrais seulement proposer quelques remarques.

Le «groupe professionnel local» identifié par J.-P. Darré chez les éleveurs du Ternois et ailleurs (1985: 29-30) est un groupe virtuel (il ne se réunit jamais formellement), un groupe coactif (ses membres ont des activités semblables) et un groupe de pairs (les exploitants trop différents de la moyenne n'en font pas partie). Son extension est celle de l'interconnaissance individuelle, elle coïncide habituellement avec le territoire communal. Enfin, le groupe fait partie d'une «communauté technique» plus vaste, étendue à toute la région où le système technique pratiqué par le GPL est en vigueur. Les membres de cette communauté ne se connaissent pas individuellement, mais ils se reconnaissent comme tels lorsqu'ils se rencontrent.

Lesquelles de ces caractéristiques sont propres au cas étudié (des exploitants d'une certaine taille, $d$ 'une certaine région et producteurs de lait...), lesquelles se retrouvent ailleurs? L'auteur lui-même note qu'il n'a pas d'informations sur les régions de grande culture. La question est particulièrement intéressante pour l'industrie. On n'y dispose pas, semble-t-il, d'étude faite exactement dans les mêmes perspectives que celle de J.-P. Darré. Mais les recherches sont suffisamment nombreuses pour pouvoir y trouver quelques éléments de comparaison. 
Je ne reviens pas sur le fait que ces recherches ont un caractère de plus en plus ethnologique. Cette constatation, qui n'était pas absolument évidente au départ (pour moi en tout cas), a fait me semble-t-il l'unanimité des participants à la Table ronde de Royaumont (22-23 janvier 1987). Des travaux de cette Table ronde et de ceux que j'ai pu consulter par ailleurs ressortent, à mon avis, deux modèles opposés de l'entreprise industrielle. Je les appellerai modèle de l'entreprise-corps, et modèle de l'autonomie ouvrière.

Dans l'image de l'entreprise-corps, c'est la priorité donnée à la cohésion interne de l'ensemble de l'entreprise qui est particulièrement évidente. Cette cohésion peut être obtenue par des moyens plus ou moins violents, et l'entreprise apparaît alors comme disciplinaire. Plus souvent, on cherche à l'obtenir par des moyens idéologiques qui vont du simple paternalisme à l'élaboration de véritables cultures ou religions d'entreprise. Le spectre des références est large: l'entreprise tient tantôt de la caserne, tantôt du pensionnat ou du couvent, tantôt de la maison de correction, de la prison, de la secte. Dans certains cas extrêmes, on en vient même à se demander lequel des deux objectifs, produire ou discipliner les hommes, est le plus important. Et les cas de ce genre paraissent avoir eu une telle importance au XIX ${ }^{\mathrm{e}}$ siècle qu'il est permis de se demander si le passage de la "proto-industrie» (je conteste le terme) à la grande industrie est dû à des nécessités objectives d'organisation du travail, ou s'il ne répond pas plutôt au besoin d'encadrer, de former, de façonner pour ainsi dire les ex-ruraux pour en faire une masse de manœuvre utilisable comme une armée. Il est essentiel, bien entendu, de ne pas interpréter ces faits en termes moraux: ce qui nous choque aujourd'hui n'est pas ce qui choquait les contemporains, et l'histoire est assez difficile à comprendre comme cela sans que nous venions brouiller le tableau avec nos jugements. Mais il est essentiel aussi de savoir que tout cela n'a pas pris fin avec le $\mathrm{xIX}^{\mathrm{e}}$ siècle, tant s'en faut. Le modèle japonais, que les économistes occidentaux ont découvert à grand bruit dans les années 1970, relève parfaitement du modèle de l'entreprise-corps. On s'est d'ailleurs aperçu depuis - effet de miroir, heuristique de la différence - que certaines de nos entreprises les plus performantes d'Occident (IBM, ITT, Michelin, Peugeot...) ressemblaient beaucoup au modèle japonais! Les moyens d'assurer la cohésion de l'entreprise ne sont plus les mêmes (on ne chante plus l'hymne d'IBM depuis 1945). Mais l'objectif de cohésion, lui, n’a pas changé. Et il serait erroné de penser qu'il est simplement imposé d'en haut. Les entreprises-corps qui marchent le mieux sont celles où, grâce à divers mécanismes d'équilibrage, l'objectif de cohésion arrive à être partagé par l'ensemble du personnel.

Quant au modèle de l'autonomie ouvrière, c'est peut-être dans l'imprimerie qu'il s'est réalisé de la façon la plus évidente et la plus classique, avec le système dit de la commandite (Saulnier-Thiercelin et Masson 1984: 86 sq.). Dans ce système, l'équipe ouvrière qui se charge d'une certaine tâche s'organise comme elle l'entend, et elle négocie sa rémunération globale avec son donneur d'ordres (l'imprimeur) sur la base d'un tarif précis. Avec tous les détails qui le caractérisent, le système de la comman- 
dite est sans doute particulier à l'imprimerie, comme l'affirment les auteurs cités. Mais si on s'en tient aux principes - autonomie dans le travail, rémunération négociée pour chaque tâche avec l'employeur - son occurrence paraît beaucoup plus large. On le retrouve aux chantiers navals de Port-de-Bouc, dans la chapellerie à Chazelles-sur-Lyon, peutêtre dans la ganterie à Saint-Junien, dans le cycle à Saint-Étienne... Et il est probable que les exemples se multiplieraient si on les cherchait vraiment. Si on ne l'a pas fait, c'est parce que le modèle de la grande industrie (de l'entreprise-corps, en réalité) a trop longtemps été considéré comme la norme, par rapport à laquelle il ne pouvait y avoir qu'archaïsmes ou exceptions. (C'est pour cette raison que le terme de proto-industrie me paraît inacceptable.) Or si une chose est sûre, c'est que le modèle de l'autonomie ouvrière n'est pas archaïque. Dans l'imprimerie, il n'apparaît que vers la fin du $\mathrm{xI}^{\mathrm{e}}$ siècle. À Port-de-Bouc, il est plus récent encore.

Mais ce qui est tout spécialement intéressant pour nous, me semble-t-il, c'est le mode d'apprentissage qu'il implique. Partout où on observe une certaine autonomie ouvrière, en effet, on s'aperçoit qu'il n'existe pas d'enseignement formel du métier, mais que chaque jeune qui veut l'apprendre doit se trouver un ouvrier qualifié qui consente à le prendre avec lui pour les quelques mois ou années que durera son apprentissage. La relation qui se noue ainsi ne fait en général l'objet d'aucune formalisation écrite ou juridique. Elle n'en est pas moins soumise à des règles très strictes qui en font un véritable contrat. $\mathrm{Et}$, aspect primordial, si le chef de l'entreprise doit évidemment autoriser l'entrée en apprentis- sage de tel ou tel, ce n'est pas lui qui en décide, mais l'ouvrier qualifié lui-même - qui, significativement, est appelé patron à Chazelles. Ainsi, l'autonomie ouvrière ne se limite pas à l'organisation interne des tâches. Elle s'étend à la formation des jeunes et à leur recrutement (car pratiquement, apprentissage réussi vaut embauche), c'est-à-dire à ce qui est une des conditions vitales de reproduction de l'industrie.

On le voit, autant l'étude de l'apprentissage était décevante sur le plan de l'explicitation des savoirs, autant elle paraît essentielle pour comprendre structure et fonctionnement d'une industrie. Non pas, nous l'avons vu, qu'il n'y ait pas transmission de savoirs au cours de l'apprentissage. Mais il y a en même temps transmission de beaucoup d'autres choses - de certaines qualités morales, entre autres - qui appartiennent évidemment à l'identité ouvrière, et qui permettent à l'apprenti de construire la sienne. L'apprentissage transmet tout ensemble: savoirs efficaces, sens et identité. Ce qui est, encore une fois, la définition de l'inculturation. Nous voyons du même coup pourquoi, peut-être, l'école marche si mal: c'est parce qu'elle n'est censée transmettre que du savoir. (Il n'en est pas ainsi en réalité, et c'est heureux. Mais on peut prévoir que l'école échouera d'autant plus qu'elle voudra se centrer plus étroitement sur ce seul objectif.) Mais nous voyons aussi pourquoi certaines industries aux structures jugées archaïques parviennent à survivre et à s'adapter (Saint-Junien: Lamy 1987), alors que d'autres, beaucoup plus modernes, s'effondrent. Il est permis de se demander si une scolarisation malencontreuse n'a pas aidé à cet effondre- 
ment dans certains cas, en rompant le fil d'une transmission de savoirs que seul l'apprentissage pouvait assurer. Je me permets de rappeler que j'avais déjà explicitement posé cette question, à propos de l'agriculture à temps partiel dans les Vosges du Sud, il y a près de dix ans (Sigaut 1980).

Mais revenons à notre propos. On peut supposer, bien que nous n'en ayons pas la preuve, que lorsque nous rencontrons l'autonomie ouvrière et la forme d'apprentissage qui lui est liée, il existe des groupes professionnels locaux au sens que donne Darré à cette expression. La question est de savoir quelle est la structure de ces groupes, et comment elle varie en fonction des conditions techniques et autres. S'agit-il toujours de groupes de pairs, par exemple? Probablement pas, dans la mesure où chaque équipe ouvrière est composée de plusieurs spécialistes entre lesquels s'établit une hiérarchie. La parité serait alors entre les équipes, non entre les individus.

Il s'agirait aussi de savoir si l'apprentissage, les groupes et la communauté technique dont parle Darré existent dans les entreprises-corps, sous quelles formes, ou sinon, ce qui en tient lieu. Je n'ai ni la compétence ni les informations qui me permettraient d'aborder cette question utilement. Je voudrais pourtant ajouter une dernière remarque sur l'importance des rites qui, semble-t-il, accompagnent presque toujours le processus d'apprentissage - et dont l'existence dans le milieu des grandes écoles montre bien que l'apprentissage se réintroduit là même où on l'avait cru le plus complètement éliminé (Blanc 1987). L'étude des rites en milieu professionnel est certainement un moyen d'accès à la façon dont sont produits et transmis les savoirs. Moyen d'autant plus précieux, peut-être, que l'observation directe est difficile.

\section{Culture technique et patrimoine}

Quelles suggestions concrètes tirer, de ce qui précède, en matière de sauvegarde et de valorisation du patrimoine ethnologique? Avant d'en venir à cette question, il me semble qu'il reste une équivoque à lever. Nous avons vu combien les notions de savoir, savoir-faire, habileté, etc., étaient floues et difficiles à manier. Mais que dire de la notion de culture technique? Voilà plus de dix ans que l'expression est employée de plus en plus couramment, à tort ou à raison. Peut-on dire que l'usage en ait clarifié le contenu? Je n'en ai pas l'impression. Dans notre société, on le sait, le mot culture a deux sens: celui que lui donne l'anthropologie, qui en a produit des centaines de définitions; et celui que lui donne le langage courant. C'est dans cette seconde acception qu'il faut entendre les «deux cultures» (littéraire et scientifique) dont parlait C.P. Snow, c'est à elle aussi que se rattache la boutade bien connue d'Édouard Herriot: «La culture c'est ce qui reste quand on a tout oublié». Bien sûr, il est toujours possible de ramener la seconde acception à la première. La culture selon Herriot ou Snow est science assagie ou érudition dominée, mais elle est surtout ce qui permet de distinguer les 
personnes cultivées de celles qui le sont moins ou qui ne le sont pas. Et comme toute culture opère ce genre de distinction en identifiant l'appartenance à un groupe, on pourrait ramener la culture-Herriot au statut des cultures de l'anthropologie, en identifiant socialement le groupe des personnes cultivées qui la détient. Mais cela ne nous aiderait pas à résoudre notre difficulté. Car il y a bien quelque chose de propre à la culture-Herriot, c'est qu'elle ne doit servir directement à rien, c'est sa gratuité. Nul n'est considéré comme cultivé du fait qu'il connaît bien son métier, même si ce métier est aussi «culturel» que celui de musicien ou d'artiste peintre. La culture-Herriot, c'est une culture de spectateurs, d'amateurs, de connaisseurs, une culture de praticiens aussi à la rigueur, mais à condition que cette pratique ne serve pas à gagner sa vie. Cela étant, de quoi parlons-nous lorsque nous parlons de culture technique? Faisons-nous allusion à une culture au sens anthropologique du terme, c'est-à-dire à l'ensemble des savoirs matériels efficaces mis en œuvre dans telle ou telle profession? Ou entendons-nous par là une connaissance cultivée des techniques en général, que nous souhaitons voir davantage répandue dans le public?

Il me semble qu'il n'y a guère à hésiter. Diderot le tout premier l'avait bien compris: c'est au public lettré de son temps qu'il s'adressait, et il avait parfaitement conscience que son entreprise ne pouvait pas avoir d'autre sens que celui-là. Les données $\mathrm{du}$ problème n'ont pas changé aujourd'hui. Les cultures techniques réelles sont liées aux groupes locaux où elles sont produites. Nous pouvons les prendre comme objets de nos études, nous pouvons nous efforcer d'en retrouver par l'enquête certaines caractéristiques lorsqu'elles ont disparu. Mais nous ne pouvons pas les extraire de leurs conditions d'existence, et encore moins les reproduire. La question n'est pas seulement théorique, elle se pose très concrètement dans les reconstitutions muséales et dans les expérimentations archéologiques. Il y avait voici quinze ans des centaines de "fermes historiques vivantes» aux États-Unis (Schlebecker et Peterson 1972), et il y en a peut-être autant en Europe aujourd'hui. Mais il n'a jamais été question que les cultures n'y soient pas traitées contre certains parasites, que le bétail y reste malnutri ou non vacciné, qu'on y fasse travailler des enfants ou des esclaves... Encore ne s'agit-il là que des limites les plus banales des reconstitutions réalistes. Nous avons assez vu, dans ce rapport, qu'il y en avait bien d'autres. Et à supposer enfin que, par miracle, nous réussissions à reconstituer complètement telle ou telle chose, quelles réactions ce spectacle va-t-il provoquer? Un intérieur de paysans aisés $\mathrm{du} \mathrm{xvIII}^{\mathrm{e}}$ siècle ne va-t-il pas être interprété comme l'exemple d'une abominable misère, des femmes fardées comme à la cour de Versailles vont-elles susciter autre chose que des rires? On ne peut échapper à cette conclusion: la réalité ne se manipule pas. Le réalisme n'est pas possible, et s'il l'était, le danger n'en serait que plus grand de le voir devenir spectacle, c'est-à-dire mensonge. Car tout spectacle est artificiel, et ne peut être honnête que s'il se donne à voir pour tel. Si donc nous parlons de promouvoir ou de sauvegarder la culture technique en général, ou des savoirs techniques en particulier, il me semble que cela implique un choix clair. Ce n'est pas l'univers réel de pratique et de pensée de 
tel ou tel groupe professionnel qui peut être objet de promotion ou de sauvegarde. C'est seulement ce qui peut en être extrait au titre de cette connaissance cultivée des techniques, à laquelle je réserverai désormais le terme de culture technique.

Quel est alors le contenu d'une culture technique aujourd'hui? Il consiste en au moins deux choses, me semble-t-il: l'expérience personnelle d'une activité matérielle réussie, et une érudition technographique aussi poussée que possible.

L'expérience personnelle est évidemment indispensable parce que c'est sur elle que tout le reste repose; c'est elle, en particulier, qui donne sens à tous les enseignements que nous pourrons recevoir par la suite. (L'enseignement ne peut pas supplanter l'apprentissage, il peut seulement en élargir la portée.) La grande difficulté de notre époque est que les occasions d'acquérir une expérience technique personnelle disparaissent de plus en plus. Entre une scolarisation trop abstraite et l'enfermement des fabrications pour des raisons d'automatisme ou de sécurité, que reste-t-il aujourd'hui à qui veut confronter ses forces et son habileté aux résistances de la matière? Le bricolage, le sport, ou d'autres activités de loisir... Ce n'est pas négligeable, et nous avons $\mathrm{vu}$, par exemple, tout ce que l'archéologie et l'ethnologie maritimes doivent au public de la navigation de plaisance. Mais nous avons vu aussi quels déséquilibres en résultent.

Ces déséquilibres, seule une érudition technographique plus large, plus réfléchie et mieux partagée peut les réduire. Nous avons vu que c'est à la fois affaire d'organisation pratique et de concepts, et que l'entreprise est de longue haleine. Mais il serait néfaste de vouloir en faire l'économie sous prétexte d'aller au plus urgent. Car on retomberait très vite dans l'incohérence. On peut considérer les techniques du point de vue du praticien, on peut aussi les considérer du point de vue de l'ethnologue et de l'historien, mais tout point de vue autre que ces deux-là comporte des risques graves de dérives vers la célébration nostalgique ou la propagande idéologique. Les exemples ne manquent pas.

Cela étant dit, des urgences n'en existent pas moins, et le programme "savoirs menacés» en identifie bon nombre. Dans tel ou tel cas concret, que faire?

Il me semble que ce sont toujours les perspectives économiques qu'il faut élucider en premier lieu.

En deçà d'un certain seuil de productivité du travail, en effet, non seulement on ne pourra pas sauvegarder quoi que ce soit, mais je pense qu' on ne doit même pas s'y essayer. On ne refera pas les terrasses des Cévennes en remontant la terre à dos d'homme. On ne verra plus des femmes s'ébouillanter les doigts à longueur de journée pour tirer le fil du cocon. Et personne ne peut regretter cela.

Mais dans beaucoup de cas, la question est de savoir si c'est bien pour de vraies raisons économiques que tant de techniques ont disparu ou disparaissent. Car le calcul économique n'est pas chose facile, et il repose sur quantité de suppositions où les préjugés n'ont que trop tendance à se glisser. Combien de techniques ont-elles été ainsi vouées à l'abandon sans examen véritable? En agriculture, par exemple, on s'aperçoit qu'il y a des cas où la traction chevaline reste compétitive (Rossier 1982), et certains sont revenus à des méthodes beaucoup plus simples d'élevage du 
porc. Pourquoi ne fait-on plus de toits en chaume? Parce que les compagnies d'assurance les ont fait interdire au siècle dernier, en raison des risques d'incendie. Mais le chaume a des qualités de légèreté et $\mathrm{d}$ 'isolation thermique remarquables, et il est possible de l'ignifuger. Et je ne parle pas de la construction en terre ou en bois, qui a d'actifs partisans. Pour d'autres techniques, spécialisées et rares, c'est le hasard qui peut jouer: l'entreprise tombe aux mains de dirigeants incapables ou lointains et fait faillite, ou la prolongation de la scolarité en a écarté les apprentis...

La première tâche de l'ethnologue, me semble-t-il, est donc de démêler les bonnes et les mauvaises raisons pour lesquelles une activité paraît condamnée. Si la condamnation lui semble due à de mauvaises raisons, il pourra alors tenter d'enclencher un processus de sauvegarde. Mais ce processus, s'il réussit, cessera bientôt de n'être que sauvegarde et deviendra un processus d'innovation comme les autres.

Si par contre l'activité apparaît inéluctablement condamnée, il n'y a de sauvegarde possible qu'en conditions muséales. Cela pose, on le sait, de gigantesques problèmes, que je ne suis pas compétent pour traiter. Tout ce que je peux dire est que les chances de réussite dépendront du niveau de culture technique générale chez les responsables de la région ou de l'industrie considérée. Car on voit mal, à terme, comment de telles entreprises muséales pourraient survivre si elles ne parviennent à susciter aucun intérêt de la part des branches industrielles dont elles relèvent, dirigeants et personnels.

Mais dans tous les cas, c'est l'ossature de l'activité, constituée par les techniques, par les savoirs procéduraux, qu'il est essentiel de préserver. Car l'activité elle-même ne peut être préservée que dans des conditions nouvelles qui la feront nécessairement évoluer. La chose est évidente lorsqu'on parvient à faire reprendre l'innovation. Mais croit-on que l'artisan qui va travailler dans un musée, devant un public, conservera longtemps ses «vraies» façons de faire, et surtout qu'il les transmettra à d'éventuels successeurs? On retrouve toujours les pièges du réalisme. Le seul moyen de les déjouer, c'est de ne pas perdre de vue qu'une entreprise de sauvegarde n'a de sens que si elle contribue au développement et au partage de la culture technique, c'est-à-dire de la connaissance cultivée des techniques. Celle-ci ayant deux composantes inséparables, et également indispensables: l'expérience réfléchie d'une confrontation en la matière (et on a assez dit que cette réflexion ne pouvait qu'être de nature anthropologique), et l'érudition technographique. 


\section{Récapitulation des suggestions}

\section{Mieux organiser la recherche et l'érudition technographiques}

- Tenir un fichier d'experts, branche par branche.

- Pour les branches où c'est possible, établir un état sommaire de la situation, notamment sous l'angle des relatons entre chercheurs institutionnels, chercheurs amateurs et collectionneurs, musées et public (ex. du rapport ferroviaire de G. Ribeill).

- Réfléchir à ce qu'impliquerait la définition et le classement d'ensembles techniques de référence.

- Poursuivre la discussion sur les concepts et les méthodes nécessaires pour l'unification de la discipline.

\section{Explorer les ressources de l'interdisciplinarité}

- Par le moyen de séminaires ou tables rondes réunissant ethnologues, linguistes, historiens, psychologues, ergonomes, journalistes, etc., sur la base d'une lecture préalable par chacun des travaux des autres.

- Sur des thèmes tels que l'ethnographie par les non-ethnologues, utilisation et critiques de l'ethnologie par les autres disciplines, etc.

\section{Identifier et tirer davantage parti des situations de confrontation de savoirs d'origines sociales différentes}

- Choix professionnels et pratiques techniques de la part des immigrés.

- Situations non inégalitaires de confrontations de savoirs: néo-ruraux, agriculteurs prisonniers en Allemagne, rapports entre recherche agronomique et agriculteurs dans les régions de grande culture, etc.

- Situations inégalitaires de confrontation de savoirs: école, vulgarisation technique dans l'agriculture ou l'artisanat, etc.

- Dans certaines situations, faire appel à des chercheurs venant de pays qui ont d'autres traditions culturelles que le nôtre: pays anglo-saxons, germaniques, scandinaves, Japon, etc.

\section{Procéder à des synthèses comparatives sur certains thèmes}

- L'apprentissage

- Apprentissage classique, autonomie ouvrière et groupes professionnels de Darré.

- Existence d'un apprentissage clandestin dans les situations d'où il est théoriquement exclu; relations éventuelles avec des rites comme le bizutage.

- Ethnographie comparée des grandes entreprises.

- Enquêtes rétrospectives sur l'évitable disparition de certains savoirs.

\section{Préciser les conditions culturelles et socio-politiques de la sauvegarde des techniques menacées}

- Historique comparé des réussites et des échecs dans différents pays, en particulier pays de cultures non-européennes: Inde, Chine, Japon...

Novembre 1987 


\section{Références}

BARLey, Nigel, 1983, The Innocent Anthropologist, Harmondsworth, Penguin Books.

Beltrame, Gaston, Pierre Higelé et Michèle Salmona, 1980, Jardins maraîchers, travail du maraîchage sur le littoral est et ouest varois, CAESAR (Centre d'anthropologie économique et sociale, applications et recherches), Rapport au CORDES, miméogr., 189 p.

BINFORD, Lewis R., 1987, "Data, relativism and archeological science", Man, 22 (3): 391-404.

Blanc, Dominique, 1987, "Numéros d'hommes. Rituels d'entrée à l'École normale d'instituteurs", Terrain, 8: 52-62.

BRIL, Blandine, 1983, "Analyse d'un geste de percussion perpendiculaire lancée. La mouture du mil dans un village bambara (Dugurakoro, Mali)», Geste et image, 3.

Calame, François, 1983, Pour une étude de la charpente rurale en France. L'exemple de l'Oise, Paris, thèse miméogr., 513 p.

Connu, Roger, 1984, "Porte ouverte sur la cuisine de la recherche», Terrain, 2: 45-50.

DARRÉ, Jean-Pierre, 1981-1982, La parole et la technique. L'univers conceptuel d'éleveurs du Ternois, thèse de $3^{\mathrm{e}}$ cycle sous la dir. d'Isaac Chiva, $379 \mathrm{p}$.

- 1985, La parole et la technique. L'univers de pensée des éleveurs du Ternois, Paris, L'Harmattan.

Delbos, Geneviève, et Paul Jorion, 1984, La transmission des savoirs, Paris, Éditions de la Maison des sciences de l'homme.

Devoyod, J.-J., L. Millet et M. RousSEAU, 1987, «Rôle de la vaisselle lai- tière dans les fabrications fromagères traditionnelles", in: Histoire et géographie des fromages, Caen, Université de Caen, pp. 53-65.

Evleth, Donna, 1980, «"Ne secouez pas votre serviette, il pourrait en tomber un petit pain". Un cours sur le savoirvivre des beaux quartiers à l'usage des Américaines exilées", Le Monde, 23 mars.

FouET, Jean-Marc, 1985, Utilisation des contraintes de constructibilité en intelligence artificielle. Exposé au séminaire de M. Tibon-Cornillot, EHESS/ Collège international de philosophie, le 16 avril.

GershunY, Jonathan, 1987, «Vie quotidienne, structure économique et changement technique", Revue internationale des sciences sociales, 113: 375392.

Grosclaude, Gérard, 1987, «Le beaufort: comment il a su conserver sa tradition", in: Histoire et géographie des fromages, Caen, Université de Caen, pp. 157-162.

Haudricourt, André G., et Georges GrANAI, 1955, «Linguistique et sociologie», Cahiers internationaux de sociologie, 19 (2) : 114-129.

Herskovits, Melville J., 1952, Les bases de l'anthropologie culturelle, Paris, Payot (trad. de Man and his works, New York, A. A. Knops, 1949).

Kessing, Roger, 1987, “On anthropology as interpretive quest", Current Anthropology, 28 (3): 356-357.

KunN, Thomas S., 1983, La structure des révolutions scientifiques, Paris, Flammarion (trad. de The structure of scientific revolutions, Chicago, 1962, 2éd. 1970).

-1984, Scientific development and lexical change. The Thalheimer lectures, The 
John Hopkins University, miméogr., 123 p. (Peut être obtenu auprès du Groupe d'études sur la science, 10 rue Monsieur-le-Prince, Paris $6^{\mathrm{e}}$ ).

LATour, Bruno, 1984, "L'ethnographie des laboratoires », Cahiers STS, 5: 68-75 (voir aussi l'article de S. Woolgar dans le même $n^{\circ}$ ).

Leplat, J., et J. Pailhous, 1981, «L'acquisition des habiletés mentales: la place des techniques», Le Travail humain, 44, 2: 193-383.

LUXEREAU, Anne, 1986, "À quelle mode vais-je planter mes choux?», Terrain, 6: 47-56.

Manifeste pour le développement de la culture technique, 1981, Centre de recherche sur la culture technique, Neuilly.

Meilleur, Brien A., 1986, Alluetain ethnoecology and traditional economy: the procurement and production of plant resources in the Northern French Alps, thèse, Université de Washington, miméogr., XII-467 p.

Miquel, Annick, 1987, «La fin d'un voyage: le Mauritius coule au Cap Lopez», La Recherche, 193: 1400-1402.

Nicourt, Christian, et G. FilippI, 1987, "Approche de l'incidence des techniques sur la structuration du travail», Techniques et culture, 10 (sous presse).

Roqueplo, Philippe, 1974, Le partage du savoir, Paris, Éditions du Seuil.

Rossier, E., 1982, «Panorama des utilisations du cheval et avenir", Ethnozootechnie, 30: 83-98.

SALmona, Michèle, 1972, "Le petit entrepreneur et sa relation à l'objet économique", Éducation permanente, 16: 99-111.

- 1974, «La culture économique et technique face au développement», Options méditerranéennes, 4 (21): 47-55.
- 1980, (voir Beltrame et al.).

Salthouse, Timothy A., 1984, "The skill of typing", Scientific American, 250, 2 (trad. française dans Pour la Science, $78: 32-37)$.

Schlebecker, John T., et Gale E. Peterson, 1972, Living historical farms handbook, Washington, Smithsonian Institution Press.

Schonfeld, William R., 1985, Ethnographie du PS et du RPR, Paris, Economica. SebestiK, Jan, 1983, "The rise of the technological science", History and Technology, 1 : 25-44.

Sigaut, François, 1977, «Colloque "Ergonomie et amélioration des conditions de travail en agriculture", Rodez, 29-30 avril 1977», Études rurales, 67: 93-96 (Les actes de ce colloque ont été publiés en 1979 sous le même titre par l'IRACT, 39 allées Jules Guesde, 31000 Toulouse).

- 1980, Recension de Pays, paysans, paysages dans les Vosges du Sud, Paris, INRA-ENSAA, 1977, Études rurales, 77: 112-113.

Snow, C. P., 1959, The two cultures.

SPERBER, Dan, 1982, Le savoir des anthropologues, Paris, Hermann.

Techniques et culture, 1987, "Des idées pour observer», $\mathrm{n}^{\circ} 9$ et 10 .

\section{Documents et dossiers consultés à la Mission du Patrimoine ethnologique}

Patrimoine ethnologique, recherches 1980-1987, 39 p.

Procès-verbaux:

- Commission permanente du 22 juin 1987, 5 p.

- Conseil du Patrimoine ethnologique du 29 mars 1982, 20 p. 
- Appel d'offres 1981-1982 Ethnologie de la France, 30 avril 1981, $11+2$ p.

Le patrimoine local, un outil de développement, 1987, $299 \mathrm{p}$.

Région de Lorraine. Bilan des actions de recherche menées par la Mission du Patrimoine ethnologique et la Région de Lorraine (IXe Plan) présenté devant les membres du Conseil du Patrimoine, novembre 1987.

Bilan de la recherche 1984-1986, 12 p.

Pour l'institution de «Trésors nationaux vivants» dans le patrimoine ethnologique de la France, $3 \mathrm{p}$.

Conseil de l'Europe, Comité des Ministres. Recommandation $\mathrm{n}^{\circ} \mathrm{R}(86)$ 15 relative à la promotion des métiers artisanaux intervenant dans la conservation du patrimoine architectural, $3 \mathrm{p}$.

\section{Dossiers et rapports de fin de recherche, par régions}

\section{France}

E 8229 - D. Bonnet, État des connaissances à propos des pompes hydrauliques manuelles dans la France du XIX ${ }^{\mathrm{e}}$ siècle, 1983, 21 p. + annexes.

E 8381 - G. Ribeill et B. Fradétal, Bilan et perspectives de la culture ferroviaire, 1985, 100 p. + annexes.

M. P. - F. Saulnier-Thiercelin et D. Masson, Hommes de plomb, hommes de lumière («Les typographes, évolution d'un métier traditionnel»), 1984, $170 \mathrm{p}$.

\section{Alsace}

84.54 - B. Hell et C. Méchin, Braconner en Vosges, 1986, $174 \mathrm{p}$.
E.AO.83.59 - B. Hell, Entre chien et loup. Faits et dits de chasse dans la France de l'Est, 1985, $308 \mathrm{p}$.

AO 8242 - F. Raphaël et al., Impact de l'installation de l'électricité dans une vallée vosgienne (8 articles, 10 auteurs).

\section{Aquitaine}

E AO 8295 - R. Aufan, Évolution des techniques artisanales de fabrication des brais, poix et goudrons dans les pays de Buch et de Born de l'époque gallo-romaine à nos jours.

\section{Champagne}

84 CA 71 - C. Zarka, L'habitat des vignerons en montagne de Reims, 1987, 2 vol., 194 p.

\section{Corse}

AO 8117 - P. Simonpoli, Les plantes sauvages, savoirs et utilisations, 1982, 2 vol. (vol. 1: fichier ethnobotanique, vol. $2: 4$ articles).

\section{Languedoc}

E 83 LR 09 - C. Cartier et al., L'usine en sabots. Enquête sur l'usine de Saint-Chély-d'Apcher (Lozère), 19171940, 1983, 36 p.

8463 - Y. Pourcher et B. Rousseau, Moulins et manufactures de Lozère, histoire d'une industrie, 1983, $327 \mathrm{p}$. GR 86 LR 01 - La soie en Cévennes (dossier). 


\section{Limousin}

8008 - Y. Lami, Une symbiose entre métallurgie et agriculture. Savignac-Lédrier et les forges du Périgord, 1984, $412 \mathrm{p}$.

\section{Lorraine}

Maison du verre et du cristal. La route du cristal, Nancy, Éditions Serpenoise, 1987, 32 p.

\section{Midi-Pyrénées}

AO 8267 - C. Amiel, D. Blanc, D. Fabre et C. Fabre-Vassas, Savoirs populaires et Fenouillèdes, Toulouse, 1985, 337 p.

\section{Nord-Pas-de-Calais}

8122 - P. Lepers, Les façons culturales des maraîchers de l'Audomarois. Monographie d'une famille, 1982, $92 \mathrm{p}$.

\section{Haute-Normandie}

AO 83100 - B. Bril et A. Joubert, Gestualité et identité culturelle, 1986, 122 p. + annexes.

AO 8106 - B. Morel, Pêche et navigation en Seine de 1850 à 1950, 1984, 116 p.

\section{Pays de Loire}

AO 8215 - Les biscuiteries de Nantes du XIX ${ }^{e}$ siècle à nos jours, Nantes, Musée du Château des ducs de Bretagne, 1987, 141 p. (Catalogue d'une exposition, 22 oct. $87-2$ oct. 88 ).

AO 8141 - Écomusée de la Vendée. Étude et sauvegarde de l'architecture en terre dans le Marais breton vendéen. Le Daviaud, 1984, 24 p. + annexes.

\section{Picardie}

8027 - Charpentes et charpentiers traditionnels dans l'Oise (dossier).

\section{Provence}

7917 - Du chantier naval à la ville: la mémoire ouvrière de Port-deBouc, 242 p. (J'ai utilisé notamment «Une qualification industrielle actuelle», par A. Degenne et J. Duplex, pp. 57-90).

AO 8224 - M.-H. Guyonnet et al., Salinde-Giraud: logique industrielle, logique sociale, 1987.

E 8232 - G. Hardouin, Pêcheurs, espaces et espèces halieutiques au Lavandou (Var), 1984, 35 p. + annexes.

81 PACA 01 - G. Hardouin, Gestes, techniques et rites de la pêche martegale, $1981,27+6$ p.

\section{Rhône-Alpes}

AO 8257 - A.-M. Bardagot et N. Sabatier, Transmission des savoirs dans le métier de charpentier, 1983, 39 p.

8004 - L. Bérard et P. Marchenay, Analyse scientifique d'un système hydraulique: les étangs de la Dombes (Ain), 231 p., 1982.

81 RA 16 - P. Cayez, Espace de production et espace de travail. Les grandes usines lyonnaises au $\mathrm{xx}^{\mathrm{e}}$ siècle. Centre Pierre Léon, 1987, 189 p.

AO 8216 - La chapellerie, ses savoirfaire, 137 p. + annexes.

B. Ganne, Gens du cuir, gens du papier. Transformations d'Annonay depuis les 
années 1920, Paris, Éditions du CNRS, $1983,226 \mathrm{p}$.

84 RA 57 - N. Gérôme et A. Guiche, La danse du verre, étude avec les verriers de Saint-Just. Perception d'une identité, sauvegarde d'une profession, $1985,88 \mathrm{p}$.

\section{Saint-Pierre-et-Miquelon}

83.22 - E. Rieth et al., Recherches archéologiques, ethnologiques et historiques des Îles de Saint-Pierre-et-Miquelon, 1987, $162 \mathrm{p}$.

\section{Journées «Anthropologie} industrielle : méthodes et principaux thèmes de recherche ", Royaumont, 22-23 janvier 1987.

M. André, BSN Verrerie de Reims, une expérience culturelle dans une entreprise.

P. de Bonnault-Cornu, Le langage technique de la conserve.

D. Charrasse, Rites corporatifs et stratégies d'entreprises dans le Bassin sidérurgique de Longwy.

G. Herberich-Marx et F. Raphaël, Mémoires d'exil. Mémoires de la colonie chez les mineurs polonais du Bassin potassique d'Alsace.

G. Herberich-Marx et F. Raphaël, Les noirs et les rouges au village. Mémoires de mineurs-vignerons de Haute-Alsace.

Y. Lamy, Identité locale, culture familiale et systèmes de production.

I. Lazier, Approche ethnographique $\mathrm{d}$ 'une filière technique: quelques indications méthodologiques à travers l'étude réalisée sur les taillandiers de la Fure (Isère).
P. Mairot, Les usines-pensionnats au XIX ${ }^{\mathrm{e}}$ siècle dans le Dauphiné: culture et religion d'entreprise.

M. Périssère, Amieux conservateur nantais: un exemple de patronat social.

G. Ribeill, Cultures d'entreprises: le cas des cheminots des compagnies à la SNCF.

P. Salmeron, Description et ébauche d'analyse des rapports sociaux caractéristiques des usines textiles de la vallée de la Nièvre (Somme).

A. Vant, La dynamique de l'industrie stéphanoise du cycle vue à travers le jeu des identités.

\section{Fiches de projets}

86 FR 107 Compagnonnage.

GR 87 AL 03 Verre, potasse, textile.

CR 87 AQ 05 Artisanat et industrie, Dordogne.

86 AU 84 Hydraulique et irrigation, Vallée de la Morge.

87 BO 182 Meunerie.

86 C 47 Vannerie, enquête comparative à Fayl-Billot (52) et à Villaines-les-Rochers (37).

87 C 67 Vannerie.

GR 86 C 10 Habitat, construction.

87 CA 203 Nogentais, petite métallurgie.

87 FC 196 Arts du feu: métallurgie, verrerie, faïencerie, distillerie.

87 P 176 Métiers du meuble du Fg. St-Antoine.

87 IF 178 Innovation et évolution des savoir-faire dans l'habillement, le bâtiment et la banque.

GR 86 FR 08 Mutations des espaces industriels dans la Vallée de l'Oise.

87 LR 65 Pêche, Collioure.

87 LR 200 Vinification cachère à Gallician et Lunel. 
GR 85 LR 163 Itinéraire culturel de la soie en Cévennes.

86 LR 73 Papeteries de St-Laurent-le-Minier et Brissac depuis le $18^{\text {e }}$.

86 LI 82 Métiers du cuir, Saint-Junien.

87 PC 195 idem.

GR 86 LI 07 Changement technique, social et culturel.

87 LO 198 Verre et cristal.

86 MP 81 Le dernier martineur de cuivre à Durfort (Tarn).

86 MP 11 Meunerie, Lot.

87 NPC 194 Verre, région de Trélon.

87 NPC 207 Textile, région de Fournies (métiers à filer dits "renvideurs»).

GR 85 PL 170 Conserverie nantaise, savoir-faire, langage de travail.

87 PI 179 Technique du plâtre gros dans l'Aisne.

87 PI 205 Fromages de Rollot et brie de Meaux.

GR 87 PACA 02 Techniques fromagères et culinaires dans les Alpes du Sud.

87 PACA 199 La parfumerie à Grasse.

86 PACA 61 La pêche dans la région de Hyères.

87 RA 22 Tréfilerie, construction en terre, camionneurs.

87 RA 202 Toitures en lauzes.

87 RA 208 Conservatoire régional des cultures textiles à Roanne.

\section{Notes}

1. Il s'agit, bien sûr, d'un tableau idéalisé. La réalité est différente. Mais ce serait une autre discussion qui nous écarterait trop de notre propos ici.

2. Il est regrettable, en particulier, que Delbos et Jorion considèrent le savoir procédural comme «a-théorique», sous prétexte qu'on le trouverait dans les «manuels». Ils semblent n'avoir pas conscience qu'il y a loin d'une description technographique véritable à ces «manuels» dont on se demande, d'ailleurs, s'ils ont une réalité concrète, ou s'ils ne sont qu'une image-repoussoir faite des seuls traits caricaturaux qu'ils leur prêtent. En fait, le savoir procédural est au praticien d'une technique, mutatis mutandis, à peu près ce qu'est la grammaire pour le locuteur d'une langue. Tout locuteur connaît sa grammaire, et de façon consciente, puisqu'il peut corriger d'éventuelles erreurs. Il n'est pas pour autant à même d'en expliciter les règles comme le fait un grammairien ou un linguiste. Et réciproquement, connaître la grammaire d'une langue n'implique nullement qu'on puisse la parler: le linguiste n'est pas un polyglotte (sur tout cela, cf. Haudricourt et Granai 1955). Faut-il en conclure que dans l'étude des langues, la grammaire ne sert à rien? Delbos et Jorion ne font pourtant rien d'autre, dans leur domaine, lorsqu'ils déclarent avec quelque hauteur vouloir laisser l'étude des «contenus» aux auteurs de «manuels», parmi lesquels ils rangent selon toute apparence leur collègue P. Lemonnier (pp. 45, 108). Je n'entends pas défendre celui-ci. Mais la distinction ainsi introduite entre une haute et une basse anthropologie me semble choquante, et scientifiquement dangereuse.

3. Ces travaux portent respectivement sur la broderie au Mexique, les tissus des Andes, l'histoire du cachemire, et le tissage dans le Salento (Calabre). En France, la production d'étoffes décorées est industrialisée depuis longtemps, avec des procédés (impression sur étoffe, jacquard...) qui ont sans doute fait disparaître les savoirs comparables, à supposer qu'ils aient existé auparavant.

4. L'Inde, et surtout le Japon, offrent les meilleurs exemples d'une ergonomie qui s'attache à décrire et analyser des tâches "traditionnelles». On les trouve notamment dans le Journal of Human Ergology, édité au Japon.

5. J'eus moi-même l'occasion de l'apprendre à mes dépens avec la notion de jachère. C'est une notion tout à fait centrale pour comprendre les agricultures préindustrielles de l'Europe. Or, quand je commençai mes recherches, l'acception du terme, non seulement chez les agronomes, mais chez les géographes, les historiens et tous les autres «ruralistes», était absolument "fausse». C'est pourquoi je fis ma thèse sur d'autres techniques, l'écobuage et l'essartage.

6. Les choses sont très différentes lorsque ces savoirs sont conçus de part et d'autre comme «empiriques», c'est-à-dire sans contenu conceptuel: les scientifiques sont alors tout disposés à leur en fournir un, sous la forme $\mathrm{d}^{\prime}$ ' explications» en termes physiques ou biologiques. C'est le cas par exemple de certaines pratiques fromagères (Devoyod et al. 1987, Grosclaude 1987). Quoi que cet aspect de la recherche n'ait rien de méprisable - toute bonne technographie doit l'inclure - on comprend qu'il ne donne pas accès aux savoirs qui ont engendré ces pratiques. Il leur en substitue d'autres. 